\title{
Population Status, Habitat Use of Non-human Primates and Human-Wildlife Conflict in Zengmewerweria Forest Area, Ankober District, North-eastern Ethiopia
}

\author{
Alemayehu Bekele, Tewodros Kumssa* \\ Department of Biology, Kotebe Metropolitan University, Addis Ababa, Ethiopia \\ Email address: \\ tewodroskk@gmail.com (T. Kumssa) \\ ${ }^{*}$ Corresponding author \\ To cite this article: \\ Alemayehu Bekele, Tewodros Kumssa. Population Status, Habitat Use of Non-human Primates and Human-Wildlife Conflict in \\ Zengmewerweria Forest Area, Ankober District, North-eastern Ethiopia. Computational Biology and Bioinformatics. \\ Vol. 8, No. 2, 2020, pp. 36-42. doi: 10.11648/j.cbb.20200802.12
}

Received: October 1, 2020; Accepted: October 19, 2020; Published: October 27, 2020

\begin{abstract}
Threats to the survival of wild primate population have greatly increased. Most primate populations today face ongoing habitat disturbance, yet not all species respond to disturbance the same way, while many primate species experience declines in population density. There is no much information on the population status and density of primates in Zengmewerweria forest area. Their for study on the Population status, density, and habitat use of non-human primates and cause of human-wildlife conflict was carried out in Zengmewerweria forest area, Ankober district, north- eastern Ethiopia conducted from September 2018 to December 2020. Aim of this study was to provide information on population status, density and habitat use of non-human primate and human-wildlife conflict in the forest. Total counting method was used to collect data on the population status of non-human primates in six counting blocks. Questionnaire and group discussion were used to collect data about human-wildlife conflict as well as to assess the attitude of society about wildlife. Data were analyzed using SPSS software. Only two species of non-human primates Grivet monkey (Chlorocebus aethiops) and Black and white colobus (Colobus guereza) were identified in the forest. The total populations of Colobus guereza were 44 and 36 individuals during the dry and wet seasons respectively. There was no significant seasonal difference between seasons $\left(\chi^{2}=1.3, \mathrm{df}=1, \mathrm{P}>0.05\right)$. Similarly the total number of grivet monkey recorded during the dry season was 140 and the wet season was 117 and there was no a significant difference in the number between seasons $\left(\chi^{2}=2.6, \mathrm{df}=1 \mathrm{P}>0.05\right)$. The average density of grivet monkey and colobus was 39.67 and 12.35 individuals per kilometer square respectively. Illegal expanding for farming and illegal resource use, loss of wildlife habitat, increasing deforestation and overgrazing were the major problems encountered in the study area. Therefore, Woreda Administration should work a lot with the community to limit negative activities and protect the Forest. Furthermore, different conservation measures should be taken to increase the number of primates.
\end{abstract}

Keywords: Colobus Guereza, Forest, Grivet Monkey, Non-human-Primates, Human-wildlife Conflict, Population Estimate, Zengmewerweria

\section{Introduction}

Estimating the numbers in a primate community is important for many fields of biology and many studies base their findings on the underlying population density or abundance of the primate species being studied [22]. Understanding what processes limit primate populations, whether ecological or social, depends on knowing the population density and range sizes at any one site [5].
Extension deforestation of native trees that are main food sources for primates and the planting of commercial tree species that do not provide food sources have also contributed to increased primate crop depredation, further exacerbating human-wildlife conflicts [2]. The conversions of primate forest habitats to agricultural crops have impacted primates and other wildlife through habitat loss and fragmentation [3]. Habitat loss and fragmentation due to human activities are the most common cause for the 
extinction of species. Today, extinction of species as a result of human activities is more than 100 times faster than the natural rate of extinction and far more rapidly than new species can evolve [20]

Habitat fragmentation following expansion of human settlement and cultivated land into previous wildlife habitat the distribution of primates is highly challenging nowadays [10]. With regard to habitat use, primates occupies a wide range of habitats from riverine and montane forests to savannas, open woodland and forest edges as well as in mangrove swamps, cultivated areas and urban parks [16].

Ethiopia is a large and ecological diverse country with unique environmental conditions. Moreover, its vegetation has been deforested for various purposes. As a result, wild animals resources of the country are now largely restricted to a few protected areas [24, 13]. Currently, there are about 315 species of mammals in Ethiopia of which about 36 are endemic to Ethiopia. Primates are large, charismatic mammals found in many of the world's tropical forests. There are about 13 species of primates in Ethiopia excluding Homoe sapiens [1].

Zengmewerweria forest area is one of the areas were nonhuman primates species exists but lacks the most basic information about distribution, population status, and threats for many primate taxa in the area. So based on scientific study it is necessary to discuss about importance of wildlife with farmer communities to increase their understanding that will help to decrease rate of habitat loss due to human activities.

\section{Materials and Methods}

\subsection{Description of the Study Area}

The study was conducted in Ankober District, which is in north Shewa Zone of Amhara National Regional State in north-east-central Ethiopia. The District is situated $172 \mathrm{~km}$ from Addis Ababa, which is the Ethiopian capital, and $42 \mathrm{~km}$ to the east of Debre Berhan town which is the north Shewa Zone capital [25].

Ankober wereda had a total of 23 kebeles and the study site was included in lay debdebo kebele. Zengmewerweria forest is found in lay debdebo kebele near to the capital town of Ankober Woreda Gorebella (Figure 1). The natural forest has total area of 3,239,000 meter square.

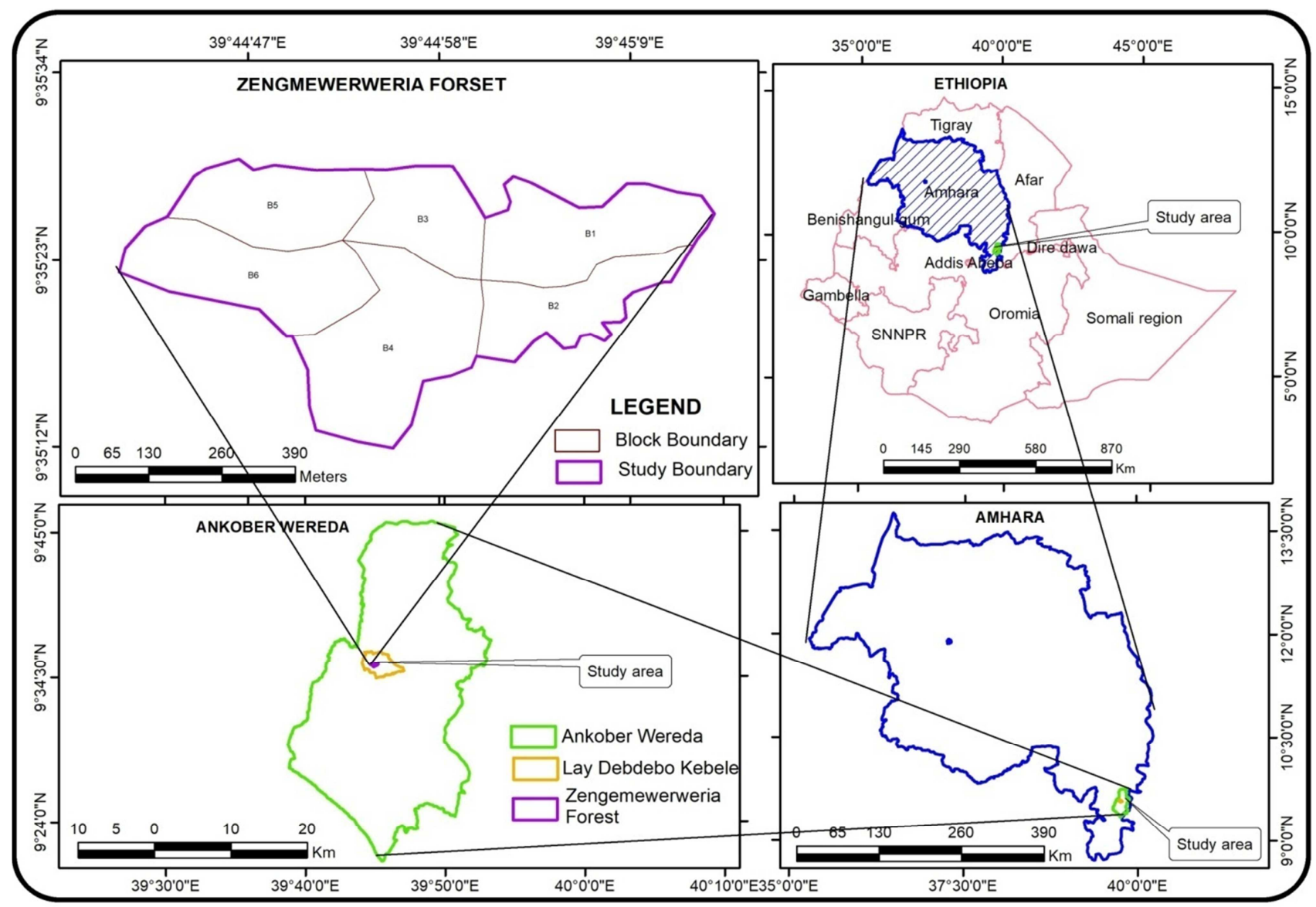

Figure 1. Map of the study area.

\subsection{Methods}

The present study was conducted from September 2018 to December 2020 which covers both wet and dry seasons.
Quantitative and qualitative data were collected during the wet and dry seasons on the population status and habitat use of the primates around the area. General Characteristics and morphology of grivet monkey was used to identify the 
species such as grivet's facial skin, hands, and feet are black. The face has a white line above the eyes. It has long white whiskers on the cheeks. The fur on the back has an olive color, while the front is white fur. The skin on the stomach area has a blue -tint.

Total counting of the species based on direct observation and silent detection was carried out to estimate the number of each species. Direct observational technique is most appropriate and effective for medium to large sized animals that live in relatively open habitats $[18,23]$. Due to the mountainous nature of the area, almost all observations have been made on foot. A total of eight counts were carried out during the wet and dry seasons in all the blocks. Each count was carried out simultaneously with the help of six trained local people of the area. During the population census, each of the individuals in the group was categorized as adult male, adult female and young by using their body structure [17].

Total count method was selected because the area to be surveyed was relatively small which has total area of 3.239 $\mathrm{km}^{2}$. According to [4] the suitability of the habitat to observe, the high mobility, the audibility of detectable signs of primate make total count method as the most effective technique especially for small area coverage or for small natural forests.

The population density of non-human primates was calculated by the following formula.

Total Density of non-human primates $=$ Number of nonhuman primates in the area /total area of blocks
At landscape level, habitat preference data was collected in the range of primates for each sighting. Habitat preferences were estimated based on observation recorded during the total counting. Habitat preferences were carried out based on the number of sightings of primates from each of the habitat types in both cases (Figure 2). Habitat preferences of primates in the study area were assessed by a combination of blocks in different habitat type and instantaneous sampling method of focal group [14]. Sightings were summarized as the total number of groups and individuals observed in each habitat type.

According to [7], differentiation of sex was done by body morphology (body and tail size) and external genitalia. Males' colobus guereza have fused gray-colored ischial callosities encircled by an unbroken ring of white hair, but in females, the gray-colored ischial callosities are separate and the encircling ring of white hair is broken into two patches. Only males of black-and-white Colobus monkey possess a large continuous line of white hairs across the perineum. Human wildlife conflict with special emphasis on non-human primate study was carried out in lay debdebo kebele which surround the Zengmewerweria forest by means of a questionnaire and focus group discussion. Both focus group discussions and questionnaires were used to collect information about attitude of farmers towards wild animals and cause of human wild life conflict.

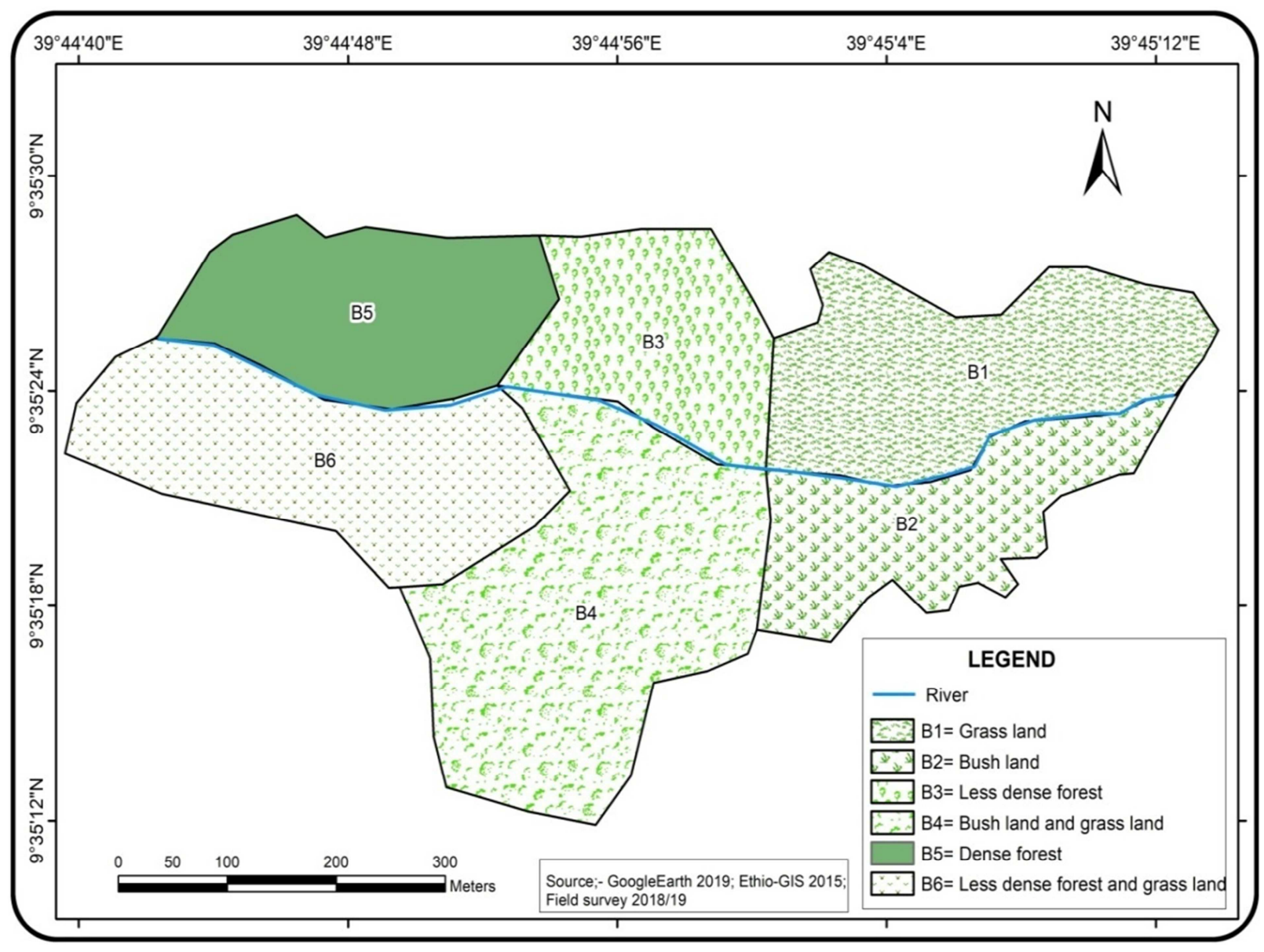

Figure 2. Map showing division of the study area and its vegetation type. 


\section{Results}

\subsection{Population Status of Primate}

In the present study, two species of primate which are Black and white colobus and Grivet monkey were identified from the study area during dry and wet seasons. Grivet monkey (Chlorocebus aethiops) individuals in the study area for both wet and dry seasons were given in Table 1. The average number of grivet monkey observed in the entire study area was 128.5 individuals. The total number of grivet monkey counted was 117 during the wet season, and 140 during the dry season. There was no significant difference between the dry and wet seasons count $\left(\chi^{2}=2.6, \mathrm{df}=1, \mathrm{P}>0.05\right)$.

Table 1. Number of grivet monkey counted during the wet and dry season (AM=adult male; AF=adult female).

\begin{tabular}{|c|c|c|c|c|c|c|c|c|c|c|}
\hline \multirow{2}{*}{ Species } & \multirow{2}{*}{ Season } & \multirow{2}{*}{\multicolumn{2}{|c|}{$\begin{array}{l}\text { AM } \\
\text { Number and } \%\end{array}$}} & \multirow{2}{*}{\multicolumn{2}{|c|}{$\begin{array}{l}\text { AF } \\
\text { Number and \% }\end{array}$}} & \multirow{2}{*}{\multicolumn{2}{|c|}{$\begin{array}{l}\text { Sub- adults } \\
\text { Number and \% }\end{array}$}} & \multirow{2}{*}{\multicolumn{2}{|c|}{$\begin{array}{l}\text { Juveniles } \\
\text { Number And \% } \\
\end{array}$}} & \multirow{2}{*}{ Total } \\
\hline & & & & & & & & & & \\
\hline \multirow{2}{*}{ Chlorocebus aethiops } & Dry & 33 & $23.6 \%$ & 49 & $35.0 \%$ & 26 & $18.6 \%$ & 32 & $22.9 \%$ & 140 \\
\hline & Wet & 23 & $19.7 \%$ & 46 & $39.3 \%$ & 21 & $17.9 \%$ & 27 & $23.1 \%$ & 117 \\
\hline
\end{tabular}

During the dry season, a total of 140 grivet monkey were counted. Out of these, there were $23.6 \%$ adult males, $35.0 \%$ adult females, $18.6 \%$ sub-adults and $22.9 \%$ Juveniles. Adult females were higher in number when compared to other groups. The number of adult females was significantly higher $(p<0.05)$ than adult males, sub-adults and Juveniles during the dry season. During the dry season, there was no significant difference between adult males, Sub- adults and Juveniles $(p>0.05)$. Based on counting blocks of the study area, the largest count during the dry season, 30\% was from block one (Table 2).

Table 2. Total Number of grivet monkey counted in each counting blocks during the dry and wet season.

\begin{tabular}{lllll}
\hline Block number & dry season & Percent & wet season & Percent \\
\hline Block 1 & 42 & $30 \%$ & 36 & $30.8 \%$ \\
Block 2 & 35 & $25 \%$ & 28 & $24 \%$ \\
Block 3 & 2 & $1.4 \%$ & 1 & $0.9 \%$ \\
Block 4 & 25 & $17.9 \%$ & 20 & $17.1 \%$ \\
Block 5 & 17 & $12.1 \%$ & 15 & $12.7 \%$ \\
Block 6 & 19 & $13.6 \%$ & 17 & $14.5 \%$ \\
Total & 140 & $100 \%$ & 117 & $100 \%$ \\
\hline
\end{tabular}

The density of grivet monkey in zengmewerweria forest was 43.22 grivet monkeys per kilometer square during dry season and 36.12 grivet monkeys per kilometer square during wet season. The average density of grivet monkey from the two seasons in the forest was 39.67 individuals per kilometer square. Out of the 140 individuals sighted during the present study observation period, adult male comprised $23.6 \%$, adult female comprised $35.0 \% \%$. The Adult male to Adult female ratio of grivet monkey was 1.00:1.49 during dry season and 1.00: 2.00 during the wet season. The age ratio of sub adults to juveniles of grivet monkey was 1.00:1.23 during dry season and 1.00: 1.29 during the wet season. The age ratios of Adult males and Adult females within the group of grivet monkey between wet and dry season was not significant $(\mathrm{p}>0.05)$. Also the Age ratios of sub-adults and juveniles of grivet monkey between wet and dry season was not significant ( $p>0.05)$.

\subsection{Habitat Preference of Grivet Monkey}

Out of the total population of grivet monkey counted during the dry season, $30 \%$ was from block one, $25 \%$ was from block two, $1.4 \%$ was from block three, $17.9 \%$ was from block four, $12.1 \%$ was from block five and $13.6 \%$ was from block six.

The total population counted at Block one which is Grass land type of habitat was significantly higher than Block three which is Less dense forest habitat type $\left(\chi^{2}=14.8, \mathrm{df}=5 \mathrm{p}<\right.$ $0.05)$, Block four Bush land and grass land habitat type $\left(\chi^{2}=12.0, \mathrm{df}=5 \mathrm{p}<0.05\right)$, Block five Dense forest habitat type $\left(\chi^{2}=12.9, \mathrm{df}=5, \mathrm{p}<0.05\right)$, and Block six Less dense forest and grass land vegetation type $\left(\chi^{2}=13.0, \mathrm{df}=5, \mathrm{p}<0.05\right)$. There was no significant difference among the total population counted at Block five and Block six $\left(\chi^{2}=7.0, \mathrm{df}=5\right.$, $\mathrm{P}>0.05)$, Block four and Block six $\left(\chi^{2}=8.5, \mathrm{df}=5, \mathrm{P}>0.05\right)$.

Related to the habitat in zengmewerweria forest maximum numbers of grivet monkeys during dry season was 42 individuals counted from Block one which is grassland type of habitat and 35 individuals counted from Block two which is Bush land type of vegetation. These two Blocks were Gorge and least disturbed by communities as a result determined number of grivet monkey were higher in these two blocks. The minimum number of grivet monkey (in average 1.5 individuals) was observed in block three as a result of high disturbance in the area.

The mean population number of Colobus guereza recorded at dry season was 44 individuals. Out of the total 44 Colobus guereza 9 individuals were adult males, 18 individuals were adult females, 8 individuals were sub-adults, and 9 individuals were juveniles (Table 3). There was no significant difference between the dry and wet seasons total count $\left(\chi^{2}=1.3, \mathrm{df}=1, \mathrm{P}>0.05\right)$.

Table 3. Total Counted Colobus guereza species with age group in the forest.

\begin{tabular}{lllllll}
\hline Species & seasons & AM & AF & Sub-adults & Juveniles & Total \\
\hline \multirow{3}{*}{ Colobus guereza } & \multirow{2}{*}{ Dry } & 9 & 18 & 8 & 9 \\
& & $20.5 \%$ & $40.9 \%$ & 15 & $18.2 \%$ & 20.5 \\
& Wet & 7 & $(41.7 \%)$ & 7 & 7 \\
& & $(19.4 \%)$ & $(19.4 \%)$ & $(19.4 \%)$ & 36 \\
\hline
\end{tabular}


During wet season the mean number of Colobus guereza was 36 individuals. Out of 36 individuals about 7 were adult males, 15 were adult females, 7 were sub-adults, and 7 individuals were juveniles. From the dry season count the largest numbers of individuals were 18 adult females and also during the wet season adult female were the largest count which was 15 individuals of adult female. The number of adult females was significantly higher than adult males, sub-adults and Juveniles during the dry season $(\mathrm{p}<0.05)$. During the dry season, there was no significant difference between adult males, Sub- adults and Juveniles $(\mathrm{p}>0.05)$.
During the wet season, there was no significant difference between adult males, Sub- adults and Juveniles $(p>0.05)$. Based on counting blocks of the study area, the largest count during the wet season, 30.8\%was from Block one (Table 4).

The Adult male to Adult female ratio of Colobus guereza was 1.00: 2.00 during dry season and 1.00: 2.14 during the wet season. The age ratio of sub adults to juveniles was 1.00:1.13 during dry season and 1.00: 1.00 during the wet season. As a result, age ratios within the Adult males and Adult females of Colobus guereza between wet and dry season was not significant ( $\mathrm{p}>0.05)$.

Table 4. Number of Colobus guereza counted in each counting blocks during the dry and wet season.

\begin{tabular}{|c|c|c|c|c|}
\hline Block number & Counted Colobus guereza during dry season & percent & Counted Colobus guereza during wet season & Percent \\
\hline Block 1 & 12 & $27.2 \%$ & 8 & $22.2 \%$ \\
\hline Block 2 & 0 & 0 & 0 & 0 \\
\hline Block 3 & 0 & 0 & 0 & 0 \\
\hline Block 4 & 16 & $36.4 \%$ & 11 & $30.6 \%$ \\
\hline Block 5 & 0 & 0 & 0 & 0 \\
\hline Block 6 & 16 & $36.4 \%$ & 17 & $47.2 \%$ \\
\hline Total & 44 & $100 \%$ & 36 & $100 \%$ \\
\hline
\end{tabular}

\subsection{Habitat Preference of Colobus Guereza}

Out of the total population of Colobus guereza counted during the wet season $22.2 \%$ was from block one, $30.6 \%$ was from block four, and $47.2 \%$ was from block six. There were no Colobus guereza counted from Block two which is bush land type, Block three which is less dense forest and there were high human activities in this block, and Block five which is dense forest type.

The total population of Colobus guereza counted at Block six which is less dense forest and grass land type of habitat was significantly higher than Block one which is Grass land type of habitat $\left(\chi^{2}=11.49, \mathrm{df}=5, \mathrm{p}<0.05\right)$, And Block four Bush land and grass land habitat type $\left(\chi^{2}=11.1, \mathrm{df}=5, \mathrm{p}<\right.$ $0.05)$.

The density of Black and white colobus (Colobus guereza) in zeng-mewerweria forest was 13.58 per kilometer square during dry season and 11.11 individuals per kilometer square during wet season. The average density of Black and white colobus was 12.35 Colobus guereza per kilometer square.

\subsection{Attitudes of the Respondents Towards Wildlife Conservation}

Respondent's was not statistically significant in determining the attitude towards wild animal conservation in gender $\left(\chi^{2}=0.914 \mathrm{df}=1, \mathrm{P}>0.05\right)$. Out of 152 respondents only 20 or $13.2 \%$ of the respondents have positive attitude towards wildlife conservation, 94 or $61.8 \%$ of them have negative attitude and 38 or $25 \%$ of the respondent's idea towards wildlife conservation is neutral. The information obtained from questionnaire show that $63.8 \%$ of the respondents not supported that of wildlife conservation, while $27 \%$ of the respondents supported wildlife conservation and $9.2 \%$ of the respondents are neutral. Education is statistically significant (elementary and secondary school education) $(\mathrm{x} 2=127.1, \mathrm{df}=3, \mathrm{P}<0.05)$ had more positive attitude than non-educated groups (illiterate and read and write only group). Out of 152 respondents 69 of them were illiterate, $(8$ with positive attitude, 44 with negative attitude, and 17 of them are neutral). Respondents which have read and write educational backgrounds are 49 (5 with positive attitude, 33 with negative attitude, and 11 of them are neutral). Respondents which have elementary educational backgrounds are 28 (4 with positive attitude, 16 with negative attitude, and 8 of them are neutral). Finally respondents with high school educational backgrounds are 6 ( 3 with positive attitude, 1 with negative attitude, and 2 of them are neutral).

$78.9 \%$ of the respondent believed that the present of forest and its area is important where as $21.1 \%$ of them believed that the forest is not important. They use different resources from the forest area according to the data obtained from questionnaire $10.5 \%$ of the respondent use the forest for fire wood, $0.7 \%$ of them use wood from the forest for construction, $1.3 \%$ use the forest for grazing and $87.5 \%$ of them use the forest for all activities including fire wood, wood for construction and for grazing. According to the respondents wild animals damage their crop as well as their livestock. The community around the forest used different method to protect their crop from wild animals especially from crop attackers. Protective mechanisms against crop damage were scarecrows, killing the animals and hung up and chasing. Those techniques were successful in minimizing the damage.

The result of group discussion summarizes the understandings of participants around study area. The participant of group discussion agreed that there was a difference when we compared the current forest status with the previous ones. All respondents $(100 \%)$ reported that the previous size of zemgmewerweria forest especially before 20 and 30 years had double size of the current coverage. From 
time to time the forest size become decrease because of different activities. The participants believed that they were the cause of deforestation. The reasons were to get more additional farm land, to use for fire wood, as well as to use for construction. So, according to the group participants the current forest size was become less and less when they compared to the previous years. Some discussants said that the current size of the forest is one third of the previous forest.

\section{Discussion}

The species which is found in zengmewerweria forest was Chlorocebus aethiops (grivet monkeys) [11] described that the grivet monkeys are distributed along the southeastern Sudan, north central Ethiopia, and Eritrea. There was a little variation in the total number of nonhuman primates counted during wet and dry seasons. The Variation in the number of grivet monkey counted in the wet and dry season was also observed in the study of [8]. Regarding to habitat preference, [6,19] described that Primates live in open habitats including deciduous forests and savanna woodlands, grasslands often extending into highland this had been true for non-human primates in the zengmewerweriya forest, meaning most non-human primates were counted from block one which is Grass land habitat type and from block two which is Bush land vegetation type. Throughout the study time they were easily found in open area. There is a river that passes through the middle of the forest, so most guerezas observed near to the river where there is no disturbance. [7] Described that Nonhuman primates lived in habitats that have trees, deciduous and evergreen forests. They are found in forests and savanna woodlands within and moist forests or around rivers.

The stability of wildlife observed in zengmewerweria is disturbed because forest Structure determines the distribution and abundance of resources, such as food and sleeping trees, which will in turn impact primate abundance, distribution and behavior. Non-human primates in the study area were suffering due to anthropogenic activities in the forest. As observed in the area there was deforestation or destruction of plants for different purpose and this affect the primate live in the forest. The same result in [12] was described as, Habitat loss and degradation challenges the survival and persistence of all forest wild-animals; however, they specifically create critical problems for arboreal animals, including all species of primates. According to $[9,22]$, attitudes in the direction of wildlife vary among rural area and between farmers. Knowledge and attitude of the people about wildlife vary from place to place. This is true in the study area because most respondents expressed negative attitudes toward wild animals including non-human primates. Around the study area the communities have negative attitudes toward wildlife. The reason is lack of information as well as knowledge about importance of wild animals. Communities with better educational background more or less have positive attitude towards wild animals. Also described by [15] the lack of knowledge or less understanding about wildlife around farmers' community leads to destruction of wildlife to get more land for agricultural practice. Primate habitats around agricultural land create the potential (or cause) for conflict between hungry primates and local people [14]. Communities around zengmewerweria forest are dependent (directly or indirectly) on the forest resources that are the main habitat for non-human primates. Because of habitat loss and fragmentation, the primates were forced to feed on agricultural crops, and this lead to human wildlife conflicts around the forest.

Deforestation as well as habitat disturbance of the study area was due to expansion of agricultural borders, resulting in threaten of wild animals. In addition to agricultural activities, other observed activities in the study area including wood harvesting, cutting trees for house building and preparing charcoals were the major cause to threats primate species.

The same thing was described by $[7,21]$ that forest fragmentations have marched together with the expansion of agricultural frontiers, resulting in both habitat loss and subdivision of the remaining habitat. The main cause of habitat destruction observed in zengmewerweria forest was due to population growth and uncertainty of land occupancy. The population growth is causes for deforestation that the farmers enforced to get additional farm land from the forest area. The same result was described in [26] habitat destruction develops the rapid decline of a large number of plants and wild animals. The loss of natural habitats as well as their disturbance is exposing wildlife to challenges. In zengmewerweria forest the components of habitat disturbance observed in the area were settlement in and around the forest, overstocking livestock and use the forest for livestock grazing were also the major problem. Grazing animals affect wildlife by avoiding natural habitat or by disturbing wildlife. [9], described that if habitats are converted to agricultural habitat loss and or pastoral land, human wild life conflicts are bound to increase and wild animals decrease due to disturbance.

\section{References}

[1] Afework Bekele and Yalden, D. W. (2013). The Mammals of Ethiopia and Eritrea. Addis Ababa University Press, Addis Ababa, Ethiopia.

[2] Ahsan, M. F. and Uddin, M. M. (2014). Humanrhesus monkey confl ict at Rampur Village under Monohardi Upazila in Narsingdi District of Bangladesh. Journal of Threatened Taxa 6: 5905-5908.

[3] Baranga, D. Isabirye, B. G. Teichroeb, J. E. and Chapman, C. A. (2012). Crop raiding patterns of solitary and social groups of red-tailed monkeys on cocoa pods in Uganda. Tropical Conservation Science 5: 104-111.

[4] Beehner, J. C., G. Birhanu, T. J. Bergmanand Mc Cann, C. (2007). Population estimate for geladas (The ropithecus gelada) living in and around the Simien Mountains National Park, Ethiopia. Ethio. J. Biol. Sci., 30: 149-154. 
[5] Chauhan, A., and Pirta, R. S. (2010). Socio-ecology of two species of non-human primates, rhesus monkey (Macaca mulatta) and Hanuman langur (Semnopithecus entellus) in Shimla, Himachal Pradesh. Journal of Human Ecology 30: $171-177$.

[6] Cowlishaw, G. and Dunbar, R. (2000). Primate Conservation Biology. University of Chicago Press, Chicago.

[7] Fashing P (1999). The Behavioral Ecology of an African Colobine Monkey: Diet, Range Use and Patterns of Intergroup Aggression in Eastern Black and White Colobus Monkeys (Colobusguereza). Ph. D. dissertation, Columbia University, New York.

[8] Getachew Gebeyehu and Afework Bekele (2009). Humanwildlife conflict in zegiepeninsula (ethiopia) with emphasis on grivet monkey (cercopithecus aethiops aethiops. Ethiop. J. Sci. 32 (2): 99-108.

[9] Hill, C. M. (2000). Conflict of interest between people and baboons: crop raiding in Uganda. International Journal of Primatology, 21 (2), 299-315.

[10] Isabirye-Basuta, G. M and Lwanga, J. S. (2008) Primate populations and their interactions with changing habitats. Int. J. Primatol. 29: 35-48.

[11] Kingdon, J. (1997). The Kingdon Field Guideto African Mammals. Academic Press, London. 476 pp.

[12] Lehman, S. M. (2004). Distribution and diversity of primates in Guyana: species- area relationships and riverine barriers. International Journal of Primatology, 25: 73-95.

[13] Leykun Abune (2000). The challenge of conserving Ethiopian Wildlife: Overview. Walia 31: 51.

[14] Mekonnen A, Bekele A, Fashing PJ, Lernould JM, Atickem A \& Stenseth NC (2012) Newly discovered Bale Monkey populations in forest fragments in southern Ethiopia: Evidence of cropraiding, hybridization with Grivets, and other conservation threats. American Journal of Primatology. 74: 423-432.

[15] Messmer, T. A. (2000). The emergence of human-wildlife conflict management: turning challenges into opportunities, Inter. Biodet. Biodegr. 49: 97-102.

[16] Michalski, F. and Peres, C. A. (2005). Anthropogenic determinants of primate and carnivore local extinctions in a fragmented forest landscape of southern Amazonia. Biol. Conserv. 124: 383- 396.

[17] Mori, A., T. Iwamoto, U. mori and Afework Bekele, (1999). Sociological and demographic characteristics of a recently found arsigelada population in Ethiopia. Primates, 40: 365381.

[18] Norton-Griffiths, M. (1978). Counting Animals 2ndedn. African Wildlife Leadership, Nairobi.

[19] Plumptre, A. J. (2000). Monitor in gmammal populations with line transect techniques in African forests. Journal of applied Ecology 37: 356-368.

[20] Primack, R. B. (2002). Essentials of Conservation Biology. Sinauer Associates, Inc. Publishers, Massachusetts.

[21] Ricklefs, R. E. and Miller, G. L. (2000) Ecology. $4^{\text {th }}$ Edition, W. H. Freeman and Company, New York.

[22] Sharma, G., Ram, C. D. and Rajpurohit, L. S. (2011). Study of man-monkey conflict and its management in Jodhpur, Rajasthan (India). Evolutionary Biology Research 3: 1-3.

[23] Sutherland, W. J. (1996). Ecological Census Techniqu. A Hand Book. Cambridge University Press, Landon.

[24] Tewodros Kumssa and Afework Bekele, (2008). Human wildlife conflict and population status of Swayne"s Hartebeestin (Alcelaphusbuselap husswaynei) in Senkele Swayne es Harte beests anctuary Master Thesis in Biology (EcologicalandSystematic Zoology), Ethiopia.

[25] ZatewE, Yemane B: Millenium Ankober. (2007). Gorebela: Ankober District, Culture and Tourism Office.

[26] ZinnerD., PeláezF., TorklerF.(2002)., Distribution and habitat of grivet monkeys (Cercopithecus aethiops aethiops) ineastern and central Eritrea African Journal of Ecology, Wiley Online Library. 